ing to the Oligocene regression. It was during this period also that the gneisses and schists of the High Himalaya were produced, although the precise mechanism of formation has not yet been worked out. In any event, the narrow gneiss-schist zone formed some way to the south of the northern margin of the original Indian block, effectively splitting off the northernmost $100 \mathrm{~km}$ or so of the Indian crust. By the early Miocene the reduced frictional resistance in the gneiss-schist zone enabled the southern segment of the Indian lithospheric block to begin underthrusting; and by 5 million years ago it had underthrust both the original northern segment of the Indian crust and part of the Asian crust (not lithosphere). Where underthrusting had occurred there was, of course, a double layer of crust; and the resulting gradual isostatic uplift added to the upthrust of the Himalayas which had commenced as soon as the underthrusting began, as well as producing the Tibetan plateau. In fact, the Himalayas did not reach their present elevation until late Pliocene or Pleistocene, which fact led Gannser (Geology of the Himalayas, Wiley-Interscience, 1964) to speculate that prehistoric man may have witnessed their rise.

This is, of course, just an outline of the processes described in greater detail by Powell and Conaghan, who go on to give supporting evidence from seafloor spreading rates and from the sedimentation patterns in the deep sea fans associated with the Indus and Ganges/ Brahmaputra river systems. But the central point is clear-the Himalayas were produced not directly by the continent-continent collision but indirectly by the subsequent underthrusting. As a result, since the early Miocene the active tectonic zone has been not the original site of continental collision marked by the Indus-Brahmaputra suture but the central crystalline axis of the gneissschist zone marking the High Himalaya (where current seismic activity is greatest). A more detailed consideration of the processes involved also explains why the Himalayan chain fails to conform with the three Dewey-Bird criteria for recognising single-stage collision-type mountain building.

\section{Transitions in the sarcoplasmic reticulum}

from a Correspondent

Measurement of the effects of temperature on transport processes in several microbial systems has led to correlations between mobility of lipids and transport activity. More detailed experiments with purified transport systems are beginning to appear. Even with these simplified systems the results are interpretable only in the most general terms, as shown by a thorough examination of the $\mathrm{Ca}^{2+}$ transporting vesicles from sarcoplasmic reticulum (Inesi, Millman and Eletr, $J$. molec. Biol., 81, 483; 1973). These vesicles contain few proteins and the major one, a $\mathrm{Ca}^{2+}$ activated ATPase which accounts for $70 \%$ of the membrane protein, is by itself able to transport $\mathrm{Ca}^{2+}$ across the membrane. The lipids are highly unsaturated and little cholesterol is present.

In earlier papers Inesi et al. reported changes in the slope of Arrhenius plots of the motion of several different nitroxide spin labels either linked to the - $\mathrm{SH}$ groups of the ATPase or incorporated into the lipid bilayer. The spin-labelled fatty acids in the lipid bilayer gave a change in slope at about $20^{\circ} \mathrm{C}$ which was not affected by prior heat denaturation of the protein. The maleimide spin labels coupled to the ATPase protein also showed a slightly increased slope below $20^{\circ} \mathrm{C}$, and a more marked one above $40^{\circ} \mathrm{C}$. The low temperature change seems to be a function mainly of the lipid phase since it can be correlated approximately with a change in rate of $\mathrm{Ca}^{2+}$ transport by a lipid soluble ionophore (Scarpa et al., J.gen. Physiol., $60,735 ; 1972)$. The nature of the change is obscure since the main orderdisorder transition in systems of highly unsaturated lipids is below $-20^{\circ} \mathrm{C}$, but a parallel may be provided by changes in physical and transport properties of other unsaturated lipid systems in the neighbourhood of $+20^{\circ} \mathrm{C}$ (for example, Esfahani et al., Proc. natn. Acad. Sci. U.S.A., 68, 3180; 1971).

In their latest paper, Inesi et al. have correlated these two transitions with changes in ATPase activity and in the rate of $\mathrm{Ca}^{2+}$ transport. When the temperature was increased above $20^{\circ} \mathrm{C}$, the heat of activation of both processes decreased from the very high value of 27 kcal $\mathrm{mol}^{-1}$ to $17 \mathrm{kcal} \mathrm{mol}^{-1}$. It therefore seems that changes in the lipid environment are reflected in changes in activity of the protein. Above $40^{\circ} \mathrm{C}$, net $\mathrm{Ca}^{2+}$ uptake ceased but ATPase activity continued unchanged; other evidence suggested that a change in the protein was involved. It is of interest that in the course of their recent determination of the diffusion constants of phospholipids in sarcoplasmic reticulum membranes, Scandella, Devalux and McConnell, Proc. natn. Acad. Sci. U.S.A. $69,, 2056$; 1972) found that this loss of $\mathrm{Ca}^{2+}$ transport at $40^{\circ} \mathrm{C}$ was prevented by $30 \%$ sucrose. This is but one of many examples of the sensitivity of this system to changes in the environment.

Although these transitions undoubtedly reflect interesting happenings within the sarcoplasmic reticulum, it will not. be possible to interpret them in molecular terms until one has a better under- standing of the structure of the ATPase protein and can incorporate it in a fully functional state into well sealed vesicles of purified lipids.

\section{Quick measurement of carrier mobility}

from our Solid State Physics

Correspondent

Among experimental solid state physicists, the interpretation and measurement of carrier mobility in semiconductors or insulators has an aura of difficulty. Not only is the path of an electron, drifting in a field within a solid, influenced by many different forms of scattering (for example interaction with phonons, inpurities and vacancies in a variety of charge states) but the measurement is not simple. For the usual Hall method, precision-cut samples with at least four low resistance ohmic contacts are needed and the resulting 'Hall mobility' has to be corrected in order to find actual drift mobility. This characteristic of earriers must, however, still very frequently be determined during research on semiconductors and so much time and patience are expended by physicists in getting valid mobility data. That is why, when a 'quick' method for the measurement of mobility is announced, interest is naturally aroused.

Howes (Rev. Scient. Instrum., 44, 1223 ; 1973) has described an evaluation of a 'direct-reading' method, using measurement of magneto-resistance by a nulling technique, involving two terminals rather than four. The latter feature brings advantages over and above the obvious one that preparation time is reduced. Many gallium arsenide transferred-electron devices, made for microwave generation studies, already have the right geometry of semiconductor chip and thus two correlated measurements can be performed on the same sample. This is particularly important when, as is often the case, different samples, even if cut from the same semiconductor ingot, may exhibit different impurity concentrations and carrier mobility values.

The new method relies on the fact that, for a sample of low aspect ratio (distance between terminals small compared with other dimensions), the applications of a magnetic field produces a reduced current flow. This results from the fact that, unlike the case of 'Hall bars' (which have a high aspect ratio) the transverse 'Hall Ficld' is not suffirient to overcome the Lorentz force which always reduces the near free path of carriers in the direction of the current flow. The decrease of this mean free path is reflected in the current passed for a given voltage and, in fact, a simple 